\title{
A FORMA URBANA PERSITENTE: gênese e metamorfose da praça na área central de Vitória
}

The persistent urban form: genesis and metamorphosis of the square in the central area of Vitoria

\author{
Botechia, Flavia Ribeiro; \\ (Prefeitura de Vitória) \\ flaviabotechia@gmail.com
}

\section{RESUMEN}

Esta pesquisa insere-se no campo teórico da morfologia urbana, o qual considera a cidade como um objeto passível de ser estudado no tempo a partir de sua forma física ordinária, e dialoga com o interesse sobre a longevidade das formas urbanas, temática que permeia algumas das obras de Lavedan (1926), Conzen (1960), Portas (2005), Dias Coelho (2014). Com isso, neste artigo faz-se uma investigação acerca das características morfológicas do processo de gênese e metamorfose material dos elementos urbanos constitutivos do espaço público da cidade de Vitória, Espírito Santo - Brasil, mais especificamente das 15 praças existentes dentro dos limites da área histórica e central.

Palabras clave: persistência, morfologia, projeto urbano, praça.

Bloque temático: morfologías urbanas.

\begin{abstract}
This research is part of the theoretical field of urban morphology, which considers the city as an object that can be studied in time from its ordinary physical form and dialogues with the interest on the longevity of urban forms, a theme that permeates some of the works by Lavedan (1926), Conzen (1960), Portas (2005), Dias Coelho (2014). Thus, in this article proceeds to an investigation about the morphological characteristics of the genesis and material metamorphosis attributed to the urban elements that constitute Vitoria's public space (Espirito Santo - Brazil), specifically about 15 existing squares in the limits of the historical and central area.
\end{abstract}

Keywords: persistence, morphology, urban design, square.

Topic: urban morphology 


\section{Introdução}

Em termos conceituais e para o Resilient Design Institute resiliência é a capacidade de adaptação de um indivíduo, comunidade ou região às mudanças em razão da propriedade, que alguns corpos apresentam, de retornar ao estado original após uma deformação temporária. Assim, a incorporação da temática da resiliência aos estudos urbanos aponta para os desafios de se planejar o futuro pensando na imprevisibilidade, sendo necessário considerar a cidade como um sistema dinâmico e complexo que precisa se adaptar a vários desafios em, pelo menos, quatro escalas: funcional (geração de receita), organizacional (governança), física (infraestrutura) e espacial (planejamento e design urbano).

Em se tratando da escala espacial, a origem e o significado do termo resiliência envolve um grupo diverso de abordagens e áreas temáticas. A exemplo da amplitude teórica sugerida, Meerow et al. (2016) ao elaborar uma análise bibliométrica e revisão da literatura identificaram um conjunto de definições de resiliência que, embora muitas vezes contraditórias, tencionam cinco noções: equilíbrio/ desequilíbrio; abordagem positiva/neutra/negativa; mecanismos de transformação (persistência, transição e transformação); adaptação/ adaptabilidade; tempo. Mas qual poderia ser a ligação entre resiliência e o estudo da forma urbana?

Ciente da diversidade de abordagens possíveis, propõe-se para este artigo uma aproximação a noção de resiliência pela perspectiva dos mecanismos de transformação material, mais especificamente do processo de persistência morfológica que incide, no tempo, sobre a materialidade da cidade. A imagem da mola que é distendida mas retorna à forma original é predominante na tratativa da resiliência, mas não é a única. E se a capacidade de ser resiliente envolvesse um nível de deformação permanente? E se fosse justamente esta deformação que fizesse com que a forma urbana primitiva pudesse atravessar as diversas camadas do tempo:

"A resiliência urbana refere-se à capacidade de um sistema urbano - e de todas as suas redes socioecológicas e sociotécnicas constituintes em escalas mundiais e espaciais - manter ou retornar rapidamente as funções desejadas diante de um distúrbio, se adaptar às mudanças e transformar rapidamente os sistemas que limitam a capacidade de adaptação atual ou futura" (Meerow et al., 2016:39).

Posto isso, ao considerar o viés da persistência como uma das características da resiliência e em diálogo com autores da área da morfologia e história urbanas (Lavedan, 1926; Conzen, 1960; Dias Coelho, 2007), algumas questões preliminares se destacam: qual foi o processo de formação das praças mais antigas da cidade? Qual a gênese desses espaços públicos? As atuais praças são formas persistentes de espaços públicos pretéritos? Estas perguntas embasaram a construção de um trabalho de investigação, que se encontra na primeira etapa de desenvolvimento, cujo objetivo principal é o estudo da gênese e formação material do espaço público do centro da cidade de Vitória (Espírito Santo, Brasil) mais especificamente de seus espaços de exceção, ou seja, das praças:

"O termo praça tem origem latina - platea - e a sua utilização procura identificar um espaço público, de caracter excepcional que morfologicamente, se distingue dos espaços canais constituídos pelas ruas. No entanto, a esta aparente clareza morfológica correspondem espaços muito diversificados, cobertos por uma variedade de nomenclaturas e que de forma alguma constituem uma invariante cultural" (Dias Coelho, 2007:24).

Justifica-se o desenvolvimento desta pesquisa pela sua excepcionalidade uma vez que são raras as publicações sobre praças, à escala local, com a referida temática morfológica e/ou com ênfase na interpretação cartográfica, entendendo-se com isso a existência de uma lacuna teórica passível de ser preenchida. Importante ressaltar que, predominantemente, a produção literária local versa sobre a narrativa de acontecimentos políticos, sociais e econômicos que podem ter incidido sobre a história destes espaços públicos, como é o caso do conteúdo dos livros Logradouros antigos de Vitória, de Elmo Elton, e História do Espírito Santo, de Maria Stella de Novaes. Dessa forma, a relevância científica da pesquisa reside na contribuição que esta poderá dar acerca da gênese dos espaços públicos que por hipótese passaram por um processo evolutivo sedimentado tendo como princípio gerador a persistência do sítio.

Diante de uma variedade de implantações e formas, propõe-se para este artigo a apresentação dos resultados parciais de análise métrica comparativa e diacrônica de 15 praças (Figura 1), à mesma escala pretendendose demonstrar a persistência da forma urbana. Nesta etapa foi possível comparar quatro períodos a partir do redesenho em software de georeferenciamento (QGis versão 2.14.8 - Essen) das cartografias históricas dos anos de 1767, 1909, 1931 e do ano de 2018, fundamentada esta escolha por se tratarem dos principais 
documentos com representação em planta baixa e indicação dos três elementos morfológicos básicos: rua, lote (quarteirão) e edifício.

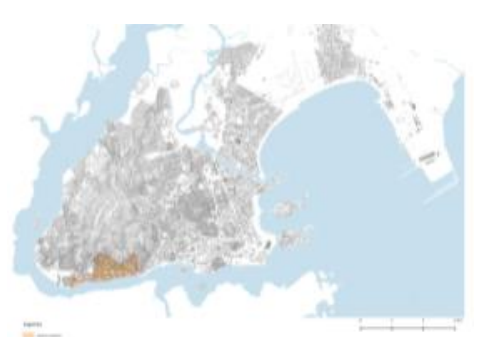

Localização do bairro Centro nos limites do município de Vitória.

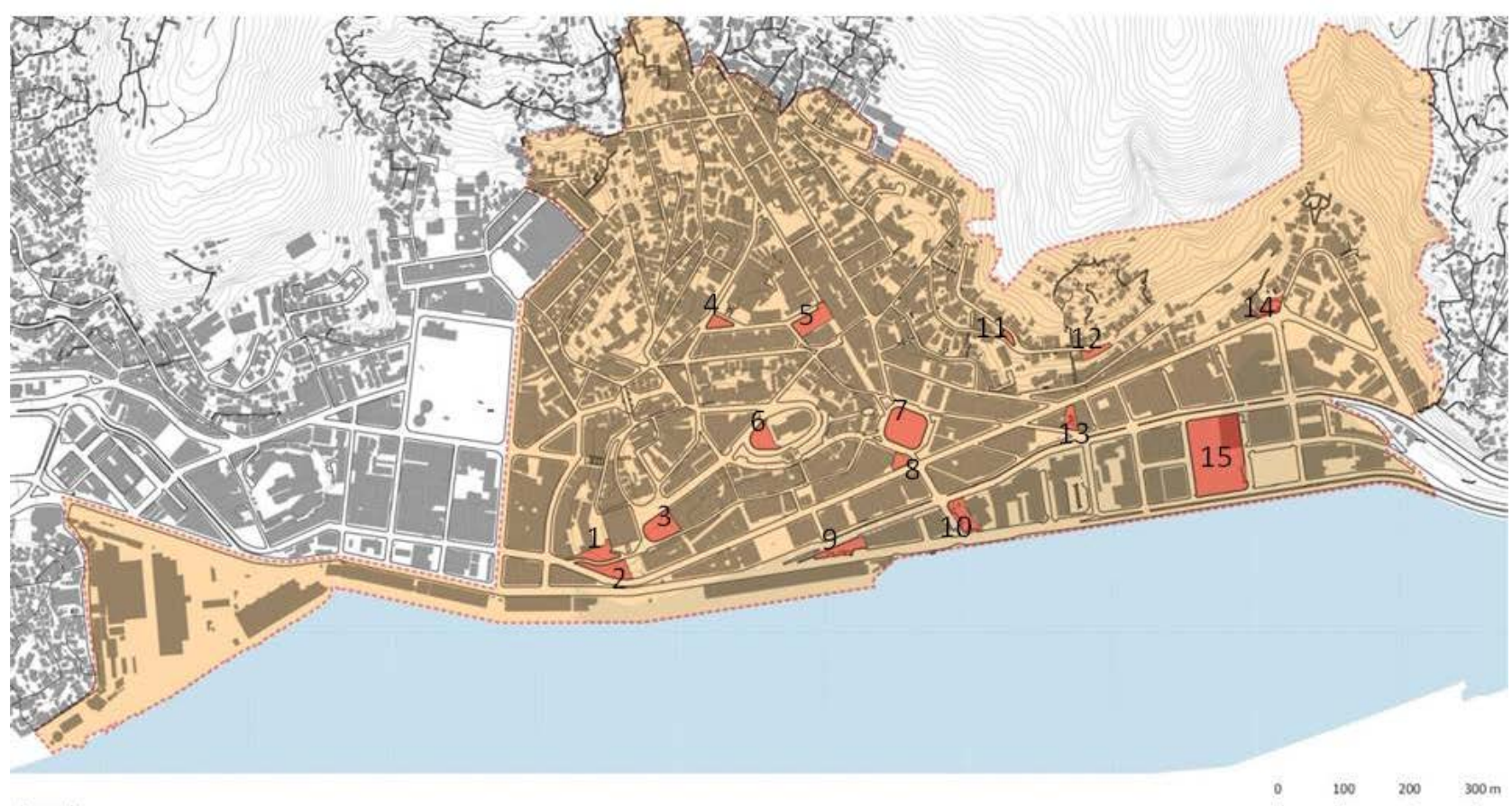

Legenda

\section{praças [2018]}

bairro Centro

Fig. 01. Mapa do bairro Centro com demarcação dos limites administrativos e das praças existentes em 2018. A identificação das Praças (reconhecidas pelo poder público municipal por meio de decretos) segundo as toponímias: 1. Praça Cecília Monteiro; 2. Praça Roosevelt; 3. Praça João Clímaco; 4. Praça Josepha Hozanah; 5. Praça Ubaldo Ramalhete Maia; 6 . Praça Dom Luiz Scortegagna; 7. Praça Costa Pereira; 8. Praça do Rotary; 9. Praça Francisco Teixeira da Cruz; 10. Praça Pio XII; 11. Praça Odilon Souza Barboza; 12. Praça Hilderico Araujo; 13. Praça Pedro Caetano; 14. Praça Manoel Silvino Monjardim; 15. Praça Getúlio Vargas. Fonte: Botechia, 2018.

Partindo-se do objetivo exposto, este artigo foi organizado em três partes. Na primeira, individualizam-se as características do fenômeno da persistência das formas urbanas por meio de revisão da literatura. Na segunda parte, explicita-se brevemente a metodologia utilizada e na terceira parte, apresentam-se os resultados e discussões parciais. 


\section{REVISÃO DA LITERATURA}

Em se tratando da história das áreas centrais urbanas é o patrimônio edificado que aflora como detentor dos vestígios materiais da memória do lugar. Nada mais do que o óbvio, a tridimensionalidade impregna, toca, assalta aos olhos, enumeram-se e nomeiam-se catedrais, claustros, castelos, edificações civis. Entretanto, estes não são os únicos remanescentes materiais do passado na cidade e, por hipótese, nem mesmo os mais antigos posto que há um nível da materialidade que vem do passado no plano bidimensional, no traçado urbano, nos espaços públicos, nas ruas e nas praças, no "chão da cidade" (Portas, 2005). Autores como Lavedan (1926), Conzen (1960), Muratori (1963), Pinon (2008), Dias Coelho (2014), dentre outros, dão especial atenção a esta questão ao tratar da identificação da persistência do espaço público, incluindo o tempo como dimensão de análise da forma naqueles tecidos que resulta de um processo sedimentar.

Pierre Lavedan é reconhecidamente um dos primeiros a fazer um estudo sistemático e aplicado sobre a persistência da forma urbana por meio de análise cartográfica. Ao identificar os elementos geradores da planta da cidade, o autor identificou uma lei, "não universal, nem absoluta", a qual denominou por loi de la persistence du plan (Lavedan, 1926:91), segundo a qual, algumas ruas da cidade perduram por séculos. Testando este argumento, para verificar aquelas formas urbanas transmitidas no tempo, Lavedan fez um estudo cartográfico tentando identificar casos empíricos de persistências: uma estrada no caso de Tell el Amarna, o plano da antiga cidade de Salonique, caminhos medievais de Fourvières, a muralha medieval convertida no eixo das avenidas em Beaumont, além de outros exemplos em Périgord, Cambridge, Paris e Munique. Assim, distintos e sucessivos períodos históricos podem ser estudados e interpretados pelo simples fato de que pode ser estabelecida uma conexão comparativa entre diferentes tempos, posto que alguns elementos permaneceram. Embora destaque-se aqui o livro de Lavedan, é importante registrar a importância de Marcel Poète e do geógrafo Raoul Blanchard que em obras de 1911 e 1922 é considerado pioneiro na defesa dos estudos comparativos dos planos urbanos para entendimento da "evolução urbana" (Tourinho, 2006).

Pierre Pinon, alguns anos mais tarde, com a publicação do artigo Défense et illustration de la "loi de persistance du plan", recuperou a questão lançada por Lavedan para identificar a persistência de fragmentos preexistentes na análise de plantas de algumas cidades francesas de fundação romana. Fez isso defendendo como método de reconstituição da materialidade do traçado, a "prospecção" retrospectiva por meio de fotografias aéreas, mapas cadastrais e análise morfológica dos tecidos urbanos. Procedendo então com a análise retrospectiva de Bourges, Amiens, D'Autin, Limoges e Paris, Pinon aponta as diferenças conceituais entre persistência e permanência (tratadas por Lavedan, no texto de 1926), e evidencia pontos fundamentais para serem observados antes de se iniciar qualquer pesquisa: a existência de tipos de plantas urbanas (de matriz colonial, ortogonal, romana, etc., a depender da história da cidade); o fenômeno da conservação do traçado (identificação preliminar de evidências topográficas, implantação de edifícios, antigos caminhos); e a possibilidade de se reconstituir as fases intermediárias da planta.

Conzen, por sua vez, ao se deter sobre análises de pequenas cidades e vilas inglesas identificou a existência de processos morfológicos que agiram sobre a substituição das formas urbanas, em três escalas: da planta da cidade, da edificação e do uso. Pelo menos dois verbetes do Glossário de termos técnicos, elaborado por este autor, fazem referência à temática abordada: Persistence of inherited forms; e Systematic differentiated persistence of forms (principle of). Na definição destes termos, Conzen afirmou que o "plano urbano" (composição bidimensional da planta da cidade) é dentre os elementos morfológicos aquele mais persistente e que a longevidade das formas urbanas está relacionada ao seu uso.

Variantes e invariantes são também objeto de avaliação de Jallon et al. (2017:47) no estudo do potencial morfológico dos edifícios do Plano Haussmann, em Paris, e sua "[...] extraordinária resiliência em termos espacial, climático, estrutural e técnico". Os autores consideraram que o edifício teve um modelo persistente e resiliente capaz de absorver as modificações das diferentes regulações urbanas, ao longo do tempo, sem desaparecer. Dentre vários mecanismos, destaca-se, no contexto da referida pesquisa, o "mecanismo do mezanino" que cria uma modulação urbana e pontos de contato entre público e privado.

Especificamente sobre as praças, as publicações de referência para esta pesquisa foram $A$ praça em Portugal; Os elementos urbanos; O tempo e a forma; além de teses e artigos dos pesquisadores vinculados ao Prof. Dr. Carlos Dias Coelho e a produção do laboratório de pesquisa FormaUrbisLab. Para Dias Coelho (2007), amparado em estudos pretéritos e diante da possibilidade de comparar retrospectivamente os elementos urbanos para deduzir os princípios que os teriam gerado, reforça-se um dos fatores que distingue as praças entre si, ou seja, sua gênese, fator pelo qual se justifica uma pesquisa dessa natureza: 


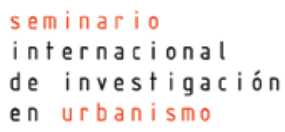

"Um dos factores que mais distingue as praças entre si é o próprio processo que as origina, isto é, se foram o resultado de um processo evolutivo que foi sedimentando progressivamente a sua forma ou, pelo contrário, se foram construídas a partir de um projecto integralmente pré-concebido" (Dias Coelho, 2007:30).

Nesta busca pela gênese, no caso português, verificou-se dentre outros resultados que equipamentos civis e religiosos estruturaram o uso e a forma dos espaços livres aos quais estavam associados. Entretanto, comparativamente no tempo, muitos dos exemplares pesquisados passaram por transformações com integral substituição de elementos tridimensionais e bidimensionais originais. Neste caso, a aferição de persistências somente se deu no que concerne a localização ou ao encontro de vias que deram origem as mesmas.

$\mathrm{Na}$ América Latina, alguns autores procederam com investigações correlatas. Waisman em $O$ interior da História (2013) enumera dez conceitos instrumentais para o desenvolvimento de estudos históricos e prática arquitetônica, dentre os quais "as durações históricas". No contexto nacional, ganhou relevância o trabalho desenvolvido por Nestor Goulart Reis, Mauricio de Almeida Abreu e Sergio Buarque de Holanda, para citar os pioneiros, dentre outros. Reis (2004), por exemplo, e em trechos selecionados, dialoga com a hipótese de que estruturas anteriores podem ter condicionado, pela continuidade, estruturas subsequentes. Desse modo seria possível identificar sinais, por meio de análise cartográfica, da direção de uma muralha, que já não existe mais, mas que persiste na composição do traçado das ruas da cidade.

A relação entre a resiliência da forma pretérita e forma atual dos espaços públicos, poderia ser identificada no centro da cidade de Vitória? A falta de estudos com este perfil sobre o referido objeto, em paralelo à identificação de cartografias nas entidades custodiadoras locais que puderam possibilitar este tipo de investigação, levou ao desenvolvimento de um estudo aplicado que se apresenta, em parte, a seguir.

\section{METODOLOGIA}

Trata-se de uma pesquisa que envolve além da formação de base teórica, obtida por meio de consulta a documentos textuais, os procedimentos de recolha documental, redesenho em software de geoprocessamento, classificação e análise comparativa de elementos urbanos individualizados.

O procedimento para coleta de dados passou por dois estágios. O primeiro compreendeu etapas de identificação de documentação, recolha documental, periodização, georreferenciamento e redesenho para equalização das representações, utilizando o software QGIS. Neste estágio foram consultados os bancos de dados de diversas instituições, tais como: Biblioteca Nacional do Brasil, Universidade Federal do Espírito Santo, Arquivo Público do Estado do Espírito Santo, Instituto Jones dos Santos Neves, Biblioteca Pública do Estado do Espírito Santo, Instituto Histórico e Geográfico do Espírito Santo, Instituto do Patrimônio Histórico e Artístico Nacional (Regional Espírito Santo), Arquivo Geral Municipal de Vitória, Centro de Documentação da Secretaria Municipal de Desenvolvimento da Cidade.

No segundo estágio, procedeu-se com a comparação entre as reconstituições de fragmentos morfológicos de tempos distintos e em escalas idênticas, além da sistematização de dados obtidos. Realizou-se a interpretação das informações fazendo um exercício comparativo das diferentes fases da forma urbana, procurando-se analisar a forma externa da praça, em planta baixa, compreendo inclusive as ruas do entorno imediato. Não foram avaliados neste momento os elementos tridimensionais do entorno (edificação), tão pouco os elementos constitutivos da praça tais como mobiliário urbano, arborização ou pavimentação. Por outro lado, buscou-se referência na literatura para construção de uma linha do tempo. De modo geral, as questões que neste momento não foram consideradas na análise, farão parte das etapas posteriores da pesquisa e serão oportunamente contempladas.

\section{RESULTADOS E DISCUSSÕES}


Com o redesenho da cartografia de 1767 foi possível verificar a existência de quatro largos defronte a cada uma das igrejas então existentes: de São Thiago e da Misericórdia, de Nossa Senhora da Vitória (matriz), de Nossa Senhora da Conceição da Prainha e do Convento de São Francisco e Santo Antônio. A respeito destes largos, a leitura de Novaes (s.d.) e Elton (1999) permitiu recuperar as toponímias que faziam referência a cada um dos edifícios religiosos, a saber: Largo do Colégio/Afonso Brás, Largo da Matriz e Prainha/Largo da Conceição. Sobre a área defronte ao Convento não foram localizados indicativos de toponímia.

Além destes espaços, sem dúvida de uso público e associados à implantação de equipamentos se notam no referido documento cartográfico alguns espaços livres, construídos provavelmente com função comercial, na forma de estruturas que avançavam sobre a linha d'agua do tipo cais, com destaque para a inscrição no mapa: "trapiche que foi dos padres da Companhia". Nota-se ainda neste mesmo documento uma área central e alagada que, na literatura (Novaes, s.d), se identificou por "pelames" e ainda outra alusiva ao pelourinho junto à Casa de Câmara e Cadeia, localizada entre a Igreja da Misericórdia e a Matriz.

Com o redesenho da cartografia de 1909, foi possível verificar a existência de cinco praças, nomeadamente: João Clímaco, Pedro Palácios, Santos Dumont, Costa Pereira e Paula Castro. A primeira é uma continuidade, no tempo, do Largo do Colégio embora a forma urbana em 1909 envolva um processo de incorporação de área derivada de demolição de um quarteirão. A Praça Pedro Palácios, por sua vez, com formato retangular que se aproxima da forma da atual Rua Pedro Palácios, parece ser a extensão do lugar do pelourinho registrado no documento de 1767. Já a Praça Santos Dumont é, comparativamente à planta anterior, uma incorporação e ampliação do lugar do Cais Grande (ou Cais da Alfândega), embora ajardinada e urbanizada. A Praça Costa Pereira apresenta-se como área pública, nas imediações do antigo Largo da Conceição e a Praça Paula Castro, por fim, sobrepõe-se ao mesmo lugar do pelames:

"[1858] Cuidava o Governo de dar à cidade logradouros públicos de acordo com o desenvolvimento da população. Por isso, mediante a lei 27, de 26 de julho de 1858, desapropriou, nos Pelames, terrenos adjacentes ao Convento do Carmo e casas, que estavam arruinadas na Rua do Carmo de Baixo (Carmo pequeno) e Ladeira da Várzea, a fim de converter-se a área, desse modo conseguida, numa praça pública, arborizada, com chafariz e tanque de lavar, provido de água da Fonte Grande" (Novaes, s.d.:236).

Aparece ainda em destaque pelo desenho e pela toponímia, nesta mesma cartografia de 1909, o Jardim Municipal defronte a baía de Vitória. Nesta região litorânea também há inúmeros cais, palco de acontecimentos da cidade. Importante notar que, por comparação, não se tratam dos mesmos cais da planta de 1767, transcorridos pouco mais de um século entre um tempo e outro, a linha do litoral já não era mais a mesma tendo passado por aterros:

"[1859] Reformou-se o Cais das Colunas, fronteiro ao Palácio Provincial, onde saltariam SSMM. Construiu-se uma ponte, para o desembarque; ergueram-se dois palanques, à direita e a esquerda, junto ao referido cais. Calçou-se a Praça do Cais. Em atenção ao seu elevado destino o Cais do Desembarque, ou das Colunas, recebeu o nome de Cais do Imperador, conservado, até princípios deste século, quando se transformou em Cais Marechal Hermes. Atualmente, com o aterro do Porto é uma praça - Praça Roosevelt [...]" (Novaes, s.d.:240).

Na planta de 1931, por toponímia indicam-se 4 praças: Praça João Clímaco (Figura 2), Marechal Hermes, Oito de Setembro e Costa Pereira. Ainda há indicativos de outras quatro áreas que seriam pretéritas às atuais Praças Irmã Josepha Hozanah, Paço Municipal, Cecília Monteiro e o que, em anos posteriores, viria ser a Praça Dom Luiz Scortegagna. No sentido oposto ao processo morfológico da sobreposição/adaptação, nesta cartografia registra-se o processo de demolição do edificado em favor da ampliação do espaço livre. Um exemplo do que se relata é o "Local destinado para o edifício dos Correios e Telégrafos":

"Localizada onde foi construída a sede dos Correios e Telégrafos, inaugurada em 1934. Antes dessa construção funcionava aí o Mercado Municipal. Esse mercado foi mandado construir em 1871 pelo Presidente Francisco Pereira Correa, sendo o projeto de autoria do engenheiro Manoel Moniz Freire [...] Era um prédio de pedra com três alas, em U, com área interna e alpendres [...]. Foi demolido em 1926" (Elton, 1999:86). 


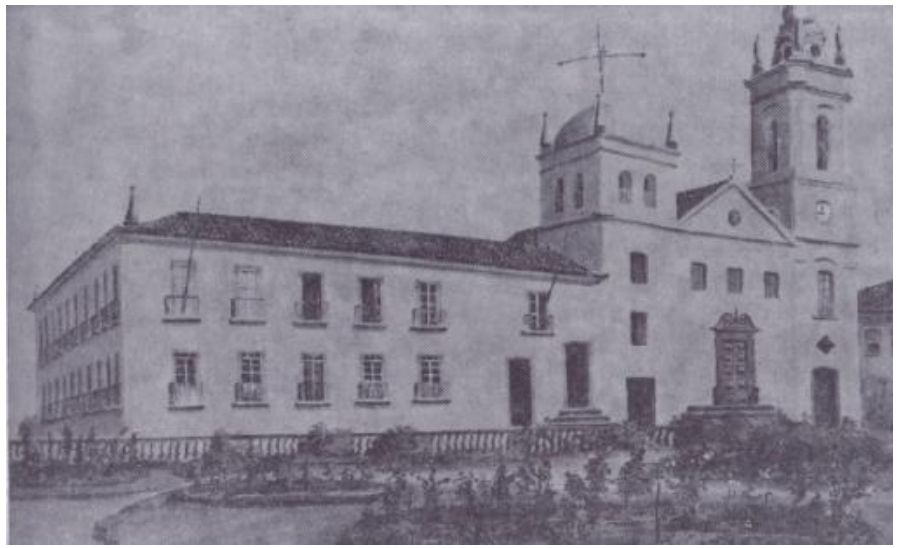

Praça do Palácio, em 1908.

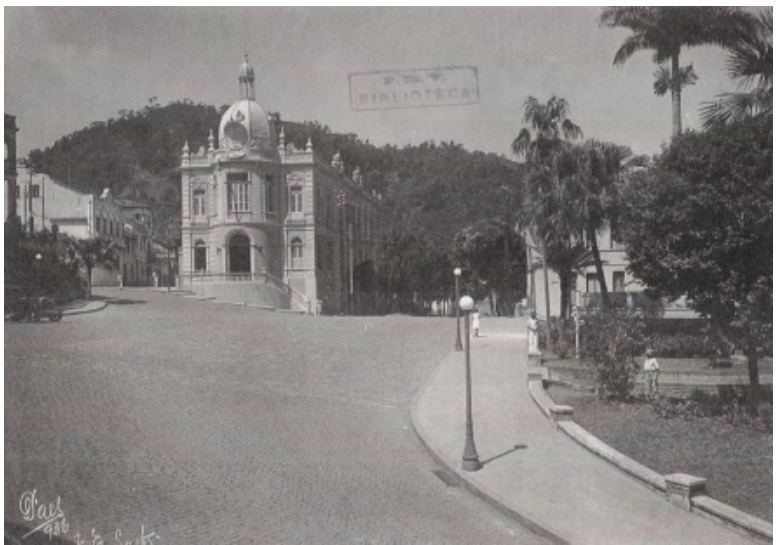

Praça João Clímaco, na década de 1930.

Fig. 02. Praça João Clímaco e suas fases em dois tempos: 1908 e 1930. Fonte: Arquivo Geral Municipal de Vitória.

\subsection{Praça Costa Pereira e Praça João Clímaco em destaque}

Consideram-se dois exemplos paradigmáticos para apresentar em detalhe os estudos diacrônicos realizados (Figura 3): a Praça Costa Pereira e a Praça João Clímaco. Justifica-se esta escolha levando-se em observação que a primeira praça é o caso de um espaço público que deriva em outro (ou seria o mesmo?), e a segunda é o caso de um espaço privado (um quarteirão) que uma vez demolido torna-se um espaço público.

No primeiro caso, no período de 1767 trata-se do Largo da Conceição defronte a Igreja de mesmo nome. No período de 1911, a igreja não parece mais uma vez que foi demolida tendo sido construído, bem próxima a localização anterior, o Teatro Melphômene; por esta razão a praça continua sendo um largo que antecede um equipamento, agora com fins de lazer, assumindo o nome de Praça do Teatro. Nesta fase é importante registrar que em função da criação do aterro a "prainha" também já não existe mais e os quarteirões ao redor do espaço público começam a se formar a partir de um aterro, dando ao espaço público um caráter central que vai ser mantido até o presente. No período de 1931, parte do que foi o espaço público é aumentado com a demolição de quarteirões, sendo agora urbanizado e ajardinado apresentando uma forma geométrica regular claramente planejada reforçando a localização central do período anterior. Em destaque nesta planta a construção do novo teatro (Carlos Gomes) e a retificação da Rua do Reguinho atual Rua 7 de Setembro.

No segundo caso, o da Praça João Clímaco, no redesenho do mapa de 1767, registra-se a existência de um largo defronte a Igreja e Colégio de São Tiago, rodeado de quarteirões por todos os lados, na região considerada o núcleo fundacional da cidade. Nesse período o espaço público é uma subtração do espaço privado, mas em nada residual posto que estava estrategicamente posicionado entre as (então) igrejas de São Tiago e de Nossa Senhora da Misericórdia. No período de 1911 aparece, a sul, o quarteirão demolido e modificado em Praça do Palácio, construída em um platô no mesmo nível do largo anterior. No período de 1931, o redesenho da planta mostra o alinhamento do espaço público, a norte, pela testada do quarteirão confrontante a Rua Pedro Palácios e, a sul, com a testada voltada para a Rua Nestor Gomes parecendo buscar, por este motivo, integração ao desenho urbano do entorno. 


\section{SIIU \\ seminario \\ internacional \\ de investigación \\ en urbanismo}
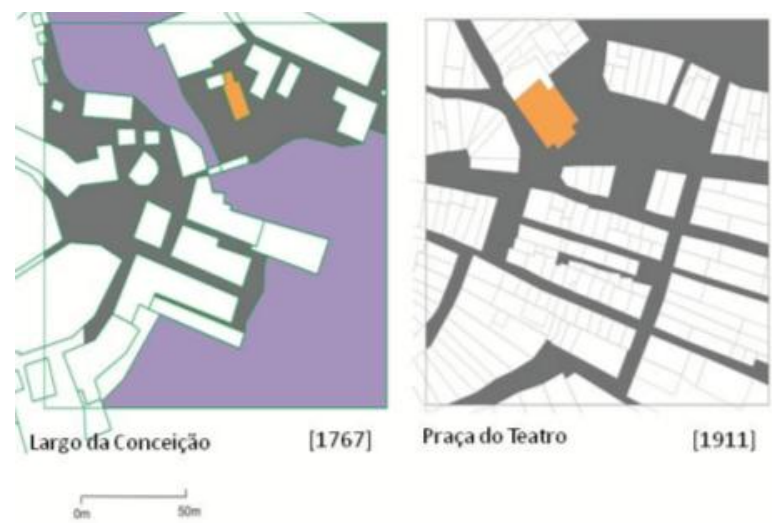

Caso 01 - Praça Costa Pereira
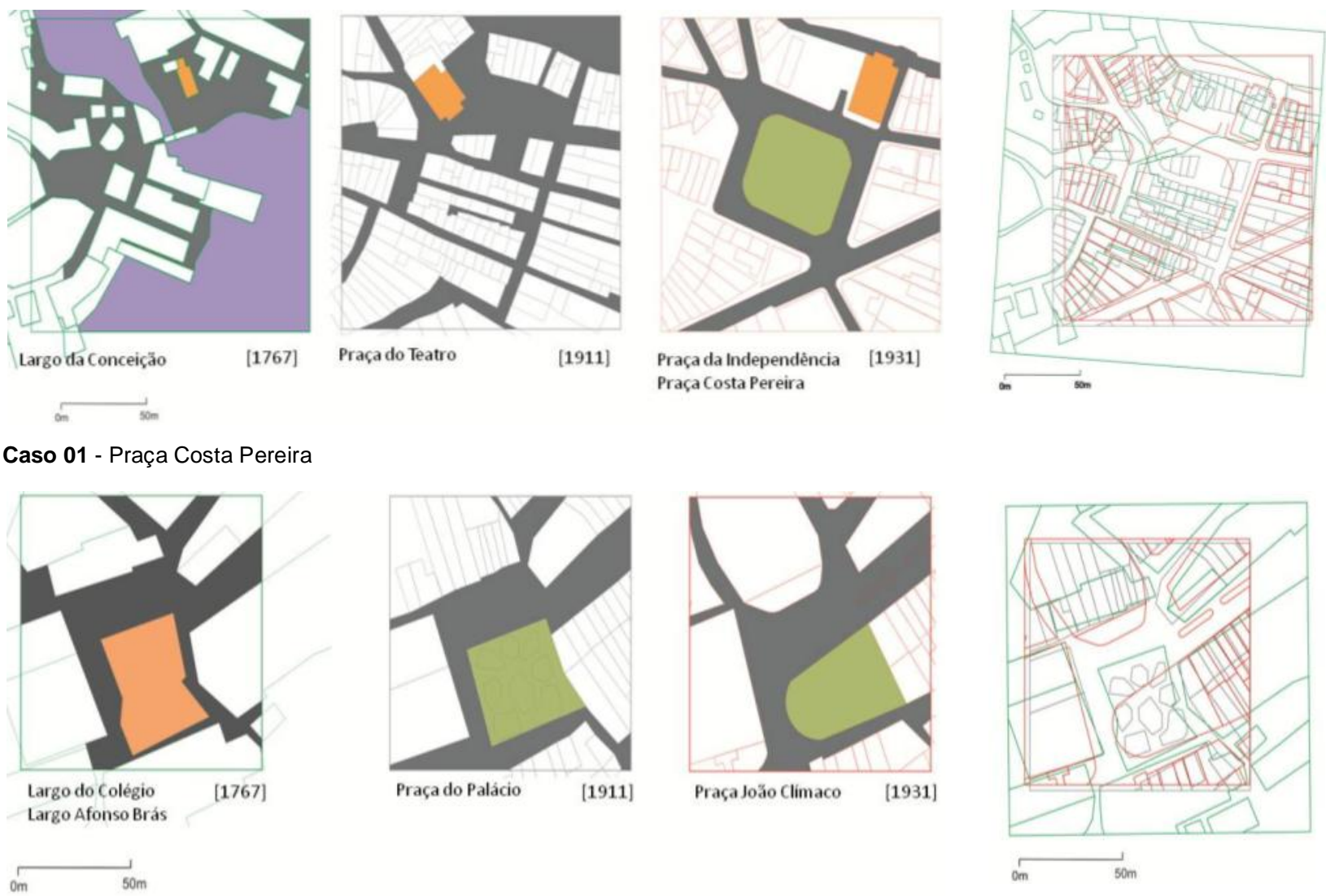

Praça da Independé
Praça Costa Pereira

$\infty$

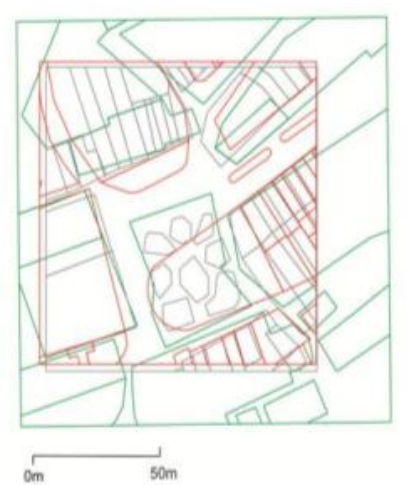

Caso 02 - Praça João Clímaco

Fig. 03. Análise diacrônica comparativa da forma das praças nos períodos de 1767, 1911 e 1931. Fonte: Botechia, 2018.

Comparativamente os dois exemplos demonstram que a primeira fase (1767) deriva de planejamento colonial com os largos posicionados frontalmente às igrejas, a segunda fase (1911) constata uma tendência à transformação do passado colonial e ao embelezamento da cidade. Na terceira fase, em 1931, indica-se o protagonismo da geometria, do ajardinamento e da demarcação de limites entre rua e praça com preocupação do desenho dos quarteirões do entorno como "fachadas". O último período de 1931 é formalmente em planta, equivale a atual forma urbana, tendo ocorrido posteriormente alterações na dimensão do edificado.

\subsection{Aspectos para discussão}

$\mathrm{Na}$ análise comparativa dos espaços públicos de exceção e do redesenho da planta baixa do bairro Centro nos anos 1767, 1909, 1931 e 2018, foi possível investigar a gênese das atuais praças do bairro (Figura 4). Com isso, a hipótese inicial de trabalho não se confirmou, posto que foram identificados pelo menos 4 princípios geradores e não somente um como argumentado inicialmente.

Das 15 praças atualmente existentes, 3 delas tem origem em projetos urbanos realizados para o solo criado por meio de aterros durante a década de 1960, são elas: Praça Francisco Teixeira da Cruz, Papa Pio XII e Getúlio Vargas. Outras 3 delas tem origem nos programas da Prefeitura de Vitória de urbanização de áreas públicas, responsáveis pela execução de projeto e obras, são elas: Praça Manoel Silvino Monjardim, Hilderico Araujo e Odilon Souza Barboza. A primeira defronte a antiga Residência Monjardim, no início da Avenida Jerônimo Monteiro, não passa de um estacionamento e as duas últimas localizadas na área de encostas do bairro tem programa simplificado sem equipamentos ou elementos de grande porte.

Outras praças tiveram gênese na demolição de quarteirões e, consequentemente, foram criadas em função de projetos eruditos de higienização e embelezamento da cidade de Vitória nas primeiras décadas do século XX: Praça João Clímaco (no seu trecho ajardinado), do Rotary, Roosevelt e trecho da Praça Dom Luiz Scortegagna. 
Podem estar envolvidos nesse processo os projetos urbanos de Viret \& Marmorat, Henrique de Novaes e Moacyr Avidos.

Por fim e em destaque tornam-se exemplo de casos de persistência de espaços públicos coloniais, principalmente de largos vinculados a equipamentos religiosos e de cais vinculados a atividades comerciais, as Praças João Clímaco, 8 de Setembro, Irmã Josepha Hozanah, Costa Pereira, Ubaldo Ramalhete Maia, Dom Luiz Scortegagna, Cecília Monteiro e Praça Roosevelt (em parte), conforme registrado no Quadro 1. Não se pode considerar que este último princípio gerador relatado seja mero exemplo de permanência da forma urbana, uma vez que houve distorção, agregação e/ou rotação da forma atual em comparação com a pretérita. Configuram-se, portanto, como casos de persistência de localização.

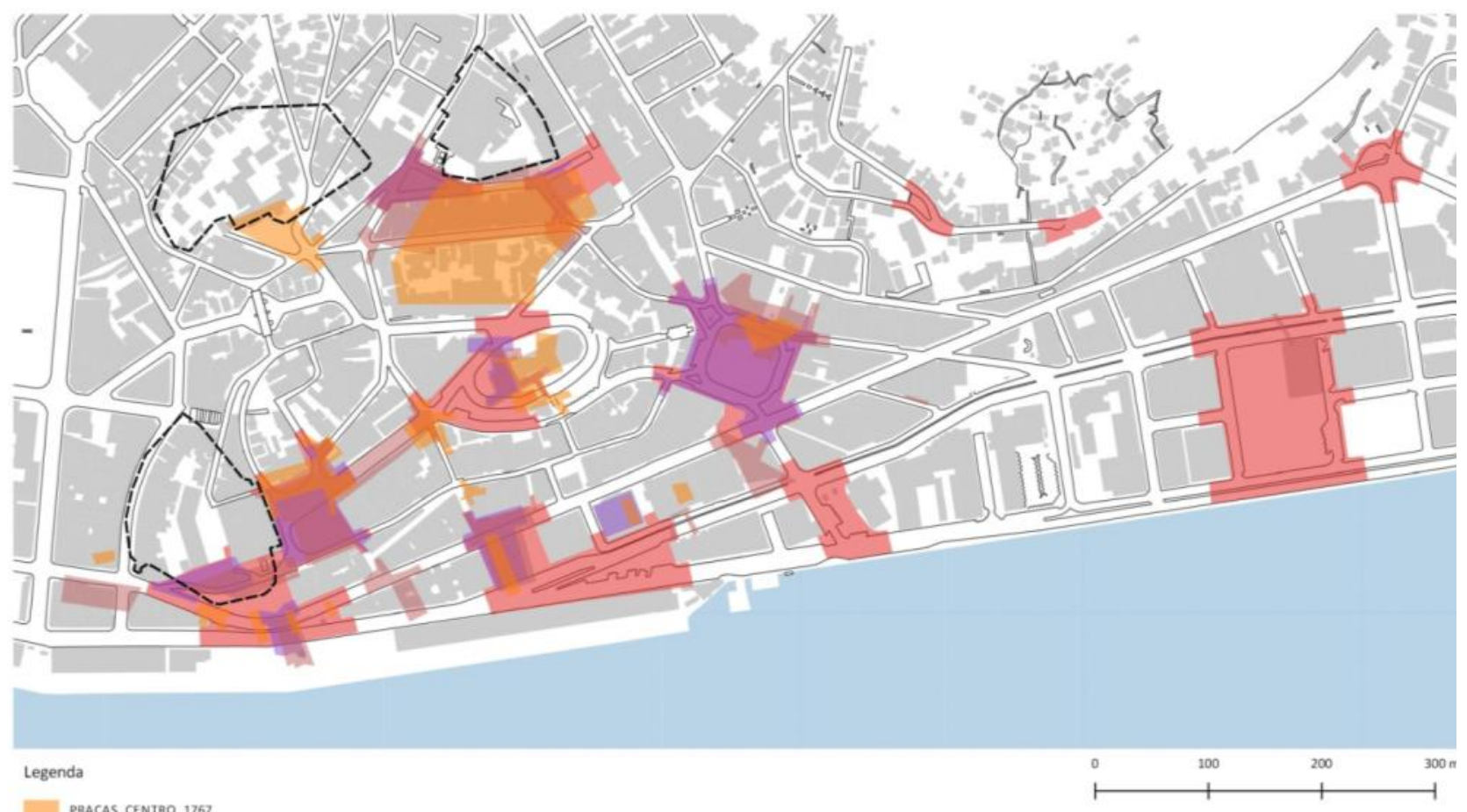

PraçAS_CENTRO_176

PRACGA_CENTRO_ 1909

PRACAA_CENTRO_1931

PRACSAS_CENTRO_2013

Limites das cercas dos conventos_1767

Fig. 04. Mapa do bairro Centro com sobreposição da demarcação do limite externo da praça nos anos pesquisados de 1767,1909 , 1931 e 2018. Fonte: Botechia, 2018.

\begin{tabular}{|l|l|l|l|}
\hline \multicolumn{1}{|c|}{$\begin{array}{c}\text { FORMA/ TOPONÍMIA } \\
\text { ATUAL }\end{array}$} & \multicolumn{3}{c|}{ FORMAS PRETÉRITASI TOPONÍMIAS PRETÉRITAS } \\
\hline João Clímaco & Largo Afonso Brás & Largo do Colégio \\
\hline Oito de Setembro & Praça Santos Dumont & Cais Grande & Cais da Alfândega \\
\hline Irmã Josepha Hozanah & Praça Paula Castro & Pelames & Largo da Conceição; Prainha. \\
\hline Costa Pereira & Praça da Independência & Praça do Teatro & Pelames \\
\hline Ubaldo Ramalhete Maia & Paço Municipal & & \\
\hline Dom Luiz Scortegagna & Largo da Matriz & & Cais e praça das colunas \\
\hline Cecília Monteiro & Jardins do Convento Jesuíta & Praça do Imperador \\
\hline Roosevelt & Praça Hermes da Fonseca & & \\
\hline
\end{tabular}

Quadro 1. Quadro comparativo da toponímia das praças cuja gênese enquadra-se em persistência do espaço público. Remeter à Figura 01 para relação entre localização e toponímias. Fonte: Botechia, 2018. 
Na pesquisa e nas avaliações realizadas também foi considerado como um dos processos, o desaparecimento (Figura 04). Isto posto, ao longo do tempo em função principalmente da alteração da linha de litoral devido a expansão da cidade, retificação, criação de ruas e execução de aterros, algumas áreas públicas desapareceram: a Praça Roosevelt (em parte) deu lugar a um cruzamento viário, a Praça João Pessoa/ Praça das Salsichas foi suprimida e edificada em seu lugar a sede dos Correios e Telégrafos, o Jardim Municipal derivou em parte do lote ocupado atualmente pelo equipamento cultural denominado "Sesc Glória", e a Praça Floriano Peixoto, de fato, ainda permite poucas especulações mas parece ter existido nas proximidades do equipamento cultural Mercado da Capixaba, situado ao longo da Avenida Jerônimo Monteiro.

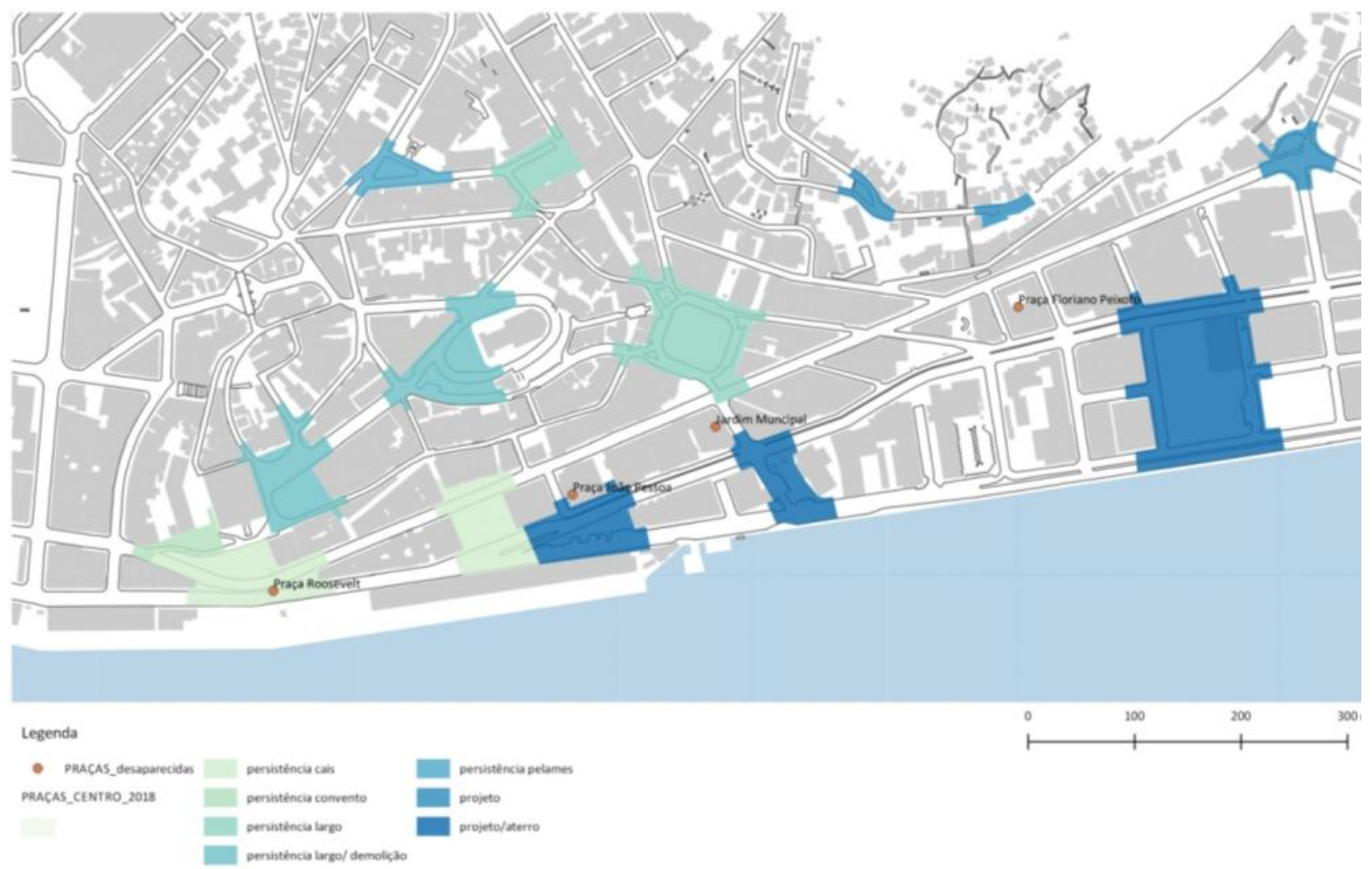

Fig.05. Mapa do bairro Centro com classificação das praças segundo sua gênese. Fonte: Botechia, 2018.

\section{COMENTÁRIOS FINAIS}

Como tudo o que dura muito tempo, a forma urbana primitiva não ultrapassou as diversas camadas do tempo sem passar por deformações, intervenções, alterações. Compreende-se com isso o espaço público como elemento fundamental e indispensável no processo de conservação da memória das cidades pois estes são mais duradouros do que os edifícios.

A pesquisa bibliográfica e cartográfica realizada lançou um ponto de luz sobre a importância do estudo da persistência do espaço público para entendimento da história urbana de Vitória, caso de estudo escolhido. Entretanto reconhece-se a necessidade de aprofundamento nas questões conceituais e metodológicas postas pela tradicional Geografia Francesa tais como Maximilien Sorre, Jean Tricart e Georges Chabot inclusive explorando as noções de situação, sítio e da utilização de mapas antigos como instrumento de metodológico.

Com a pesquisa realizada também foi possível aferir, mesmo que hipoteticamente, alguns dos motivos para a persistência das estruturas públicas pretéritas: a permanência de equipamentos civis ou religiosos que motivaram a construção dos espaços livres; e, possivelmente, as características das linhas topográficas existentes. Por consequência foi razoável entender o peso do espaço livre construindo em afinação com os 
edifícios das ordens religiosas na construção do espaço público atual da área central, mesmo que algumas daquelas igrejas já nem existam mais...

Neste momento da pesquisa não ficam claras as questões relativas a interferência de processos socioeconômicos na forma das praças senão pela verticalização do entorno, portanto, em análise bidimensional a variável gentrificação não aparece em destaque. Pelo contrário, pode-se avaliar a interferência do sítio físico pois quanto mais próxima praça do núcleo fundacional (uma colina) mais mudanças este espaço experimentou.

Após a conclusão desta primeira etapa da pesquisa relatada neste artigo, reforça-se a possibilidade de dar continuidade as pesquisas morfológicas iniciadas, detalhando-se e aprofundando-se nas questões a fim de ganhar profundidade nas reflexões iniciais.

\section{BIBLIOGRAFIA}

CONZEN, M. R. G. (1960). Alnwick, Northumberland: a study in town plan analysis. Londres: Instituto Britânico de Geografia.

DIAS COELHO, C. (2007). A praça em Portugal. Lisboa: Direcção geral do ordenamento do território.

DIAS COELHO, C. (coord.) (2014). Cadernos de morfologia urbana: o tempo e a forma. Lisboa: Argumentum. ELTON, E. (1999). Logradouros antigos em Vitória. Vitória: Edufes/ Secretaria Municipal de Cultura.

JALLON, B.; NAPOLITANO, U. y BOUTTÉ, F. (2017). Paris Haussmann: a model's relevance. Paris: Park Books, Editions du Pavillon de l'Arsenal.

LAVEDAN, P. (1926). Qu'est-ce que l'urbanisme? Paris: Laurens.

MEEROW, S.; NEWELL, J. P. y STULTS, M. (2016). Defining urban resilience: a review. Revista Landscape and Urban Planning, 147, 38-49.

MURATORI, S. et al. (1963). Studi per una operante storia urbana di Roma. Roma: Consiglio Nazionale delle Ricerche.

NOVAES, M. S. (s.d.). História do Espírito Santo. Vitória: Fundo Editorial do Espírito Santo.

PINON, P. (2008). Défense et illustration de la "loi de persistance du plan": le problème de la survivance du tracé des rues dans les villes françaises d'origine antique. En BALLET, P. et al. (coords.). La rue dans l'Antiquité: définition, aménagement, devenir. Paris: Presses Universitaires de Renne, 129-140.

PORTAS, N. (2005). Os tempos das formas: a cidade feita e refeita. Guimarães: Universidade do Minho.

REIS, N. G. (2004). São Paulo: vila, cidade, metrópole. São Paulo: Ministério da Cultura.

TOURINHO, A. de O. (2006) A Arquitetura e a Geografia Urbana na construção do urbanismo moderno e contemporâneo: em busca de uma identidade. IX Seminário da História da Cidade e do Urbanismo, São Paulo, 4-6 Setembro.

WAISMAN, M. (2013). O interior da História: historiografia arquitetônica para uso de latino-americanos. São Paulo: Perspectiva. 